\title{
Our criteria for PPH procedure in one day surgery practice
}

\author{
P. Košorok
}

Published online: 11 August 2010

(C) The Author(s) 2010. This article is published with open access at Springerlink.com

\begin{abstract}
Background The aim of this report is to analyse our results and to underline our criteria for day surgery practice.

Patients and methods Our patients are selected according to ASA criteria. Occasionally, the patients with some risk factors are selected but only when their concomitant diseases are well controlled.

Results We have treated 673 patients with the third and early fourth degree haemorrhoids. We have had patients with several minor problems causing no influence on the success of the procedure. Good haemostasis, preventing postoperative bleeding, is the most important factor.

Conclusion Among proctological procedures in haemorrhoid treatment, the PPH technique has firm and wellaccepted position even in ambulatory surgery.
\end{abstract}

Keywords Haemorrhoids - PPH procedure - Day surgery

\section{Introduction}

The prolapsing haemorrhoids are treated surgically by means of different procedures. The selection of patients for day surgery was made according to proposals of ambulatory surgery practice. In day surgery, the life of patients is minimally disturbed. Patients return to normal activities earlier, so the absence from work is negligible. Outpatient surgery is cheaper than hospital treatment, and entire health expenses are reduced [1-4].

P. Košorok $(\bowtie)$

Medicinski Center IATROS, Parmova 51B,

1000 Ljubljana, Slovenia

e-mail: Pavle.Kosorok@guest.arnes.si

\section{Patients and methods}

Between 2000 and 2010, 673 patients were treated in our day surgery unit. We are following general selection criteria for ambulatory surgery. At the beginning, we strictly followed the proposals, later supported with more experiences, we accepted also patients above 60 and not only the patients from ASA group I and II, if their health condition was generally good. However, concomitant diseases (hypertension, diabetes) must be under control. Anticoagulant medication should be stopped at the time of operation.

It is important that the patients maintain positive attitude towards ambulatory surgery. The administration should be assured that the patient has home assistance in the first $24 \mathrm{~h}$. The patient's family should be prepared to participate in the postoperative treatment. The social circumstances should be appropriate-easy access to bathroom and toilet is necessary.

\section{Preparation for surgery}

No laxatives and no enema are prescribed before operation. The patient is asked to void before anaesthesia, and an i.v. access is introduced. After induction of spinal anaesthesia, metronidazol is administered intravenously.

\section{Surgical technique}

During the operation, the patient is in gynaecological position. The operation is performed with standard Ethicon PPH stapling device. The possible bleeding on the staple line must be carefully controlled. Occasionally, when loose mucosa is observed, an elastic ring ligation must be added. 
At the end, an obstetric tampon infiltrated by $5 \mathrm{ml}$ of saline is pushed into the anus.

\section{Postoperative care}

The communication with the patient after the procedure is very important. The patient is given the telephone number of his surgeon. He can call him in case of uncertainty. We also practise to call the patient in the evening on the day of surgery. It gives the patient a very important feeling of being supervised by his surgeon. We instruct the patient and his family not to drive a car after the surgery. In case of any serious complications, the patient's home should be close enough to provide comfortable and quick access to the hospital. In case of emergency, we arrange hospital care by ourselves, which has happened only twice.

All our patients are treated in spinal anaesthesia. After the procedure, the patient is under control in the recovery room. Postoperative analgesia is given to the patients according to VAS (visual analogue scale) when the pain exceeds grade II. We use NSAID drugs (Ketoprofen, Diclofenac) or opioid analgesics (Tramadol, Metadon, Piritramid, Morfin) on demand.

The patients are given fluids orally. Great attention is paid to the possible bleeding. The patient's behaviour, general condition and secure walking are continuously followed. It is important that the patient can urinate before leaving the unit. Average discharge time after the operation for PPH (Longo) patients is $5 \mathrm{~h}$ and $8 \mathrm{~min}$.

In the first week after the procedure, the painkillers are prescribed and also Metronidazol in the first 3 days. The patient is asked to come to controls in 1 week, and later in 6 weeks after the operation. If necessary, the patient can come back immediately.

\section{Results}

Follow-up was 36 months. All patients were treated at home care. Only two of them were accepted to the hospital because of the staple line bleeding, which occurred at the beginning. Afterwards, we were very careful about this complication, and special attention was paid to the bleeding control. Minor bleeding can be well controlled by Foley catheter inflated into the anal canal.

Urine retention is the most common complication, specially after the use of stronger anaesthetic drugs (bipuvacain, marcain). Urine catheter was introduced in $8 \%$ of patients. In female patients, it is usually introduced temporarily. In case of elevated body temperature (6\%), we prescribe clindamycin. No major wound infections or abscesses were found. Headache $(6 \%)$ is connected with spinal anaesthesia. Though the pain in $\mathrm{PPH}$ procedure is minor than in classic procedures, $5 \%$ of patients suffered pain exceeding more than 7 grades on VAS scale. Sometimes $(1,5 \%)$ anal thrombosis as postoperative complication was observed.

Minor bleeding (blood on paper) on controls was seen in patients with metallic clamps or granulomas on the staple line.

Residual mucosal folds were successfully treated by means of rubber band ligations. Pain after defecation was present in patients with anal fissure. Urgent defecation or occasional minor incontinence was treated by stimulation and biofeedback. In few cases ( 6 patients), we found anal stenosis that was successfully treated with anal dilators (Dilatan).

\section{Discussion}

Stapled haemorrhoidectomy is a relatively new procedure. Many randomized controlled trials have been published, comparing the outcomes of stapled haemorrhoidopexy to conventional haemorrhoidectomy. The trials are remarkably consistent in the findings of a safe procedure, with less pain and disabled than the conventional haemorrhoidectomy [1]. The stapled haemorrhoidopexy should not be used to replace rubber band ligation but rather to be performed in patients with prolapse. Serious or even life-threatening complications are rare in experienced hands of a surgeon. The procedure is not painless, but when properly performed the pain is minimal comparing to the severe pains in classical Milligan-Morgan procedure [2]. The critical and the most difficult part of the operation is the placement of purse-string suture. It should be in the submucosal layer, $4-5 \mathrm{~cm}$ above the dentate line. It is in the low rectum, not in the upper anal canal [3, 4]. Redundant rectal mucosa must be excised during the procedure. Prolapsed internal haemorrhoids, fixed or immobile, are not suitable for stapled procedure. Patients with fibrotic anal skin tags are not suitable for PPH procedure. It is suggested to eliminate the tags later if this is indicated [5].

Stapled haemorrhoidopexy is not difficult to learn for a surgeon who is experienced at circular stapling device and anorectal surgery [6]. There were several randomized controlled trials assessing two or more treatment modalities for symptomatic haemorrhoids. Stapled haemorrhoidopexy was found to be associated with significantly less pain than conventional haemorrhoidectomy, with no significant differences in complication rate or response to the treatment [7-12].

Day case surgery has become an acceptable approach specially in proctology cases. Among proctological procedures for haemorrhoid treatment even in ambulatory surgery, PPH technique has obtained a well accepted and firm position. 
Conflict of interest The author declares that he has no conflict of interest related to the publication of his article.

Open Access This article is distributed under the terms of the Creative Commons Attribution Noncommercial License which permits any noncommercial use, distribution, and reproduction in any medium, provided the original author(s) and source are credited.

\section{References}

1. Longo A (1998) Treatment of haemorrhoidal disease by reduction of mucosa and haemorrhoidal prolapsed with a circural suturing device: a new procedure. In: Proceeding of the 6th world congress of endoscopic surgery, Rome. pp 777-784

2. Friend WG, Medwell SJ (1989) Outpatient anorectal surgery. Perspect Colon Rectal Surg 2:167-173

3. Thomas WH (2000) Stapled haemorrhoidectomy. Correspondence. Colorectal Dis 2:310

4. Sanagore A, Abcarian H, Corman M et al (2002) Safety of stapled haemorrhoidopexy. Initial results from a multicenter trial (abstract). Dis Colon Rectal 45:A22-A23

5. Corman ML, Grevie JF, Hager T et al (2003) Stapled haemorrhoidopexy: a consensus position paper by an international working party-indications, contra-indications and technique. Colorectal Dis 5:304-310
6. Macrae HM, Teruple LKF, McLeod RS (2002) A meta-analysis of haemorrhoidal treatments. Sem Colon Rectal Surg 13:77-83

7. Zacharakis E, Kanellos D, Pramateftakis MG, Kanellos I, Angelopoulos S, Mantzoros I, Betsis D (2007) Long-term results after stapled haemorrhoidopexy for fourth-degree haemorrhoids: a prospective study with median follow-up of 6 years. Tech Coloproctol 11:144-147

8. Kanellos I, Zacharakis E, Kanellos D, Pramateftakis MG, Tsachalis T, Betsis D (2006) Long-term results after stapled haemorrhoidopexy for third-degree haemorrhoids. Tech Coloproctol 10:47-49

9. Goulimaris I, Kanellos I, Christoforidis E, Mantzoros I, Odisseos Ch, Betsis D (2002) Stapled haemorrhoidectomy compared with Milligan-Morgan excision for the treatment of prolapsing haemorrhoids: a prospective study. Eur J Surg 168:621-625

10. Kanellos I, Angelopoulos S, Zacharakis E, Kanellos D, Pramateftakis MG, Blouhos K, Betsis D (2005) Stapled haemorrhoidopexy for haemorrhoids in combination with lateral internal sphincterotomy for fissure-in-ano. Eur Surg Res 37:317-320

11. Kanellos I, Blouhos K, Demetriades H, Pramateftakis MG, Betsis D (2004) Pneumomediastinum after dilatation of anal stricture following stapled hemorrhoidopexy. Tech Coloproctol 8:185-187

12. Zacharakis E, Pramateftakis MG, Kanellos D, Kanellos I, Betsis D (2007) Long-term results after transanal stapled excision of rectal internal mucosal prolapse. Tech Coloproctol 11:67-68 